Protocol

\title{
Development of Primary Monolayer Cell Model and Organotypic Model of Uterine Leiomyoma
}

\author{
Natalia Shved, Anna Egorova, Natalia Osinovskaya and Anton Kiselev *(D)
}

check for updates

Citation: Shved, N.; Egorova, A.; Osinovskaya, N.; Kiselev, A. Development of Primary Monolayer Cell Model and Organotypic Model of Uterine Leiomyoma. Methods Protoc. 2022, 5, 16. https://doi.org/ $10.3390 /$ mps5010016

Academic Editor: Lucia Monaco

Received: 3 November 2021

Accepted: 2 February 2022

Published: 6 February 2022

Publisher's Note: MDPI stays neutral with regard to jurisdictional claims in published maps and institutional affiliations.

Copyright: (C) 2022 by the authors. Licensee MDPI, Basel, Switzerland. This article is an open access article distributed under the terms and conditions of the Creative Commons Attribution (CC BY) license (https:// creativecommons.org/licenses/by/ $4.0 /)$.
Department of Genomic Medicine, D.O. Ott Research Institute of Obstetrics, Gynecology and Reproductology, MendeleevskayaLine 3, 199034 Saint-Petersburg, Russia; natashved@mail.ru (N.S.); egorova_anna@yahoo.com (A.E.); natosinovskaya@mail.ru (N.O.)

* Correspondence: ankiselev@yahoo.co.uk; Tel.: +7-812-328-9809

\begin{abstract}
Cellular technologies are one of the most promising areas of biomedicine, which is based on the isolation of cells of various types, followed by their cultivation and use, or the use of their metabolic products, for medical purposes. Today, a significant part of biomedical research is carried out in vitro. On the other hand, organotypic culture can be used as a powerful model system and can complement cell culture and in vivo studies in different biomedical applications. Uterine leiomyoma (UL) is a very common benign tumor and often leads to many reproductive complications. Herein we describe a fast and reliable method of isolation and UL primary cells culturing along with the development of a UL organotypic model. We propose the usage of UL primary cells in experimental work at a first passage to prevent loss of driver mutations in MED12 and HMGA2 genes. New optimized conditions for the growth and maintenance of 2D and 3D models of uterine leiomyoma in vitro are suggested.
\end{abstract}

Keywords: uterine leiomyoma; cell model; organotypic model; MED12; HMGA2

\section{Introduction}

Uterine leiomyomas (UL) are the most common benign tumors and represent a major public health problem in women's reproductive health. The factors affecting their growth are of great interest and are often studied in vitro using cellular models, which makes this approach a widespread model system for studying the pathogenesis and drug therapy of the disease [1-3]. Modern data convincingly indicate that somatic mutations of MED12 and rearrangements involving the HMGA2 gene are the most frequent driver mutations in UL [4]. Furthermore, new types of chromosomal deletions and translocations often appear in the myomatous nodes. Among them, the most common are translocations that occupy the chromosome region 12q14-15 and deletions of a part of the long arm of chromosome 7 [4]. A number of studies have shown that mutation inthe MED12 gene coincides with a severely reduced ability of UL cells to grow in vitro, which leads to their rapid disappearance in primary cell culture and casts doubt on the usefulness of existent UL cellular models for biomedical research [5-7].To date, several techniques have been described for the isolation of UL cell cultures but all of them cannot preserve MED12 gene mutations $[8,9]$. Primary cultures derived from UL nodes, presumably of non-tumor origin, as well as tumors carrying HMGA2 rearrangements, can survive much longer $[5,6]$.

UL is a benign tumor consisting of various cell populations (fibroblasts, smooth muscle, and stem cells) embedded in the extracellular matrix, interacting with each other, thereby ensuring proliferation. Organotypic cultures are used to study the pathogenesis and various therapeutic approaches for a number of malignant and benign tumors [10]. They retain a histological and three-dimensional structure with inter- and extracellular interactions, cellular matrix components, and intact metabolic activity. 
The aim of the present study is to developa technique for preparinga short-term monolayer cell culture and 3D organotypic model from UL tissue obtained after myomectomy or hysterectomysurgery.

\section{Experimental Design}

We have designed a protocol for the development of cellular and organotypic models from uterine fibroids obtained after myomectomy/hysterectomy. In our protocol, we describe step by step development of the models as summarized in Figure 1. This protocol will be very useful for researchers who study molecular mechanisms of UL pathogenesis and genetic alterations, and develop various therapeutic approaches. The biomaterial for the model development is dissected myomatous nodes obtained after myomectomy. The tissue slicing is performed under sterile conditions. All instruments are sterilized by autoclaving before the procedure. Cellular model development requires collagenase IV treatment to destroy UL tissue and ensure the migration of UL cells from the dissected UL fragments. In the case of an organotypic model, no enzymatic treatment is needed and bigger UL fragments $(3 \times 3 \times 3 \mathrm{~mm})$ should be left intact. The most critical component is Gibco ${ }^{\circledR}$ AmnioMAX ${ }^{\mathrm{TM}} \mathrm{C}-100$ Complete Medium, which must be used to ensure the viability of UL cells and tissues in culture. The obtained UL cell and organotypic cultures can be tested for the presence of main driver genetic alterations - mutations in exon 2 of the MED12 gene and overexpression of the HMGA2 gene. In fact, the genetic analysis should be considered as the main parameter for characterization of the obtained models.

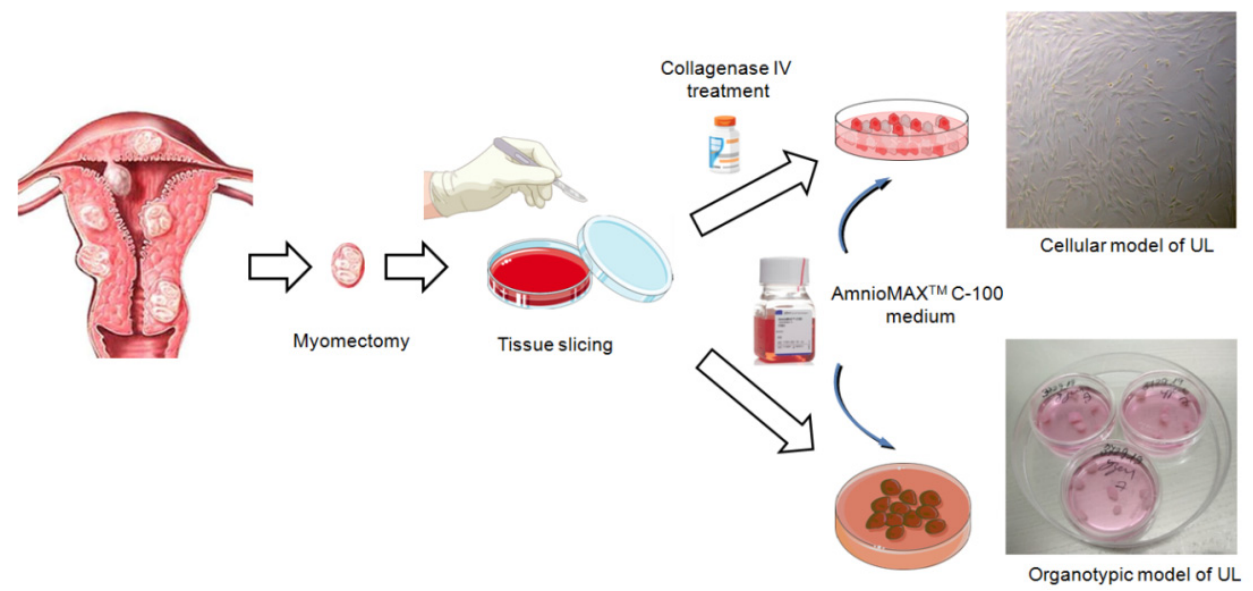

Figure 1. Representative scheme of UL cellular and organotypic model development.

\subsection{Materials}

- $\quad$ Serological pipettes (Pasteur, 3 mL, PE, PU, sterile, graduated) (Biologix, Shandong, China; Cat. no.: 30-0138A1)

- Culture bottle "T-25", for work with adhesive cell cultures (TC treated), lid with filter, sterile (Corning; Wiesbaden, Germany; Cat. no.: Corning-3815)

- Plastic sterile containers, volume 120 mL(Medpolymer, Saint-Petersburg, Russia; Cat. no.: 2620304)

- Sterile plastic Petri dishes, $94 \times 16$ mm (Greiner, Frickenhausen, Germany; Cat. no.: Greiner-633181)

- $\quad$ Sterile plastic Petri dishes, $35 \mathrm{~mm}$, for working with adherent cell cultures, ventilated (Corning, Wiesbaden, Germany; Cat. no.: Corning-353001)

- $15 \mathrm{~mL}$ volume centrifuge tubes (Corning, Wiesbaden, Germany; Cat. no.: 430053)

- $\quad 1.7 \mathrm{~mL}$ volume centrifuge tubes (Corning, Wiesbaden, Germany; Cat. no.: 3207)

- $\quad 2.0 \mathrm{~mL}$ volume centrifuge tubes (Corning, Wiesbaden, Germany; Cat. no.: 3213)

- $\quad$ PCR tubes $0.5 \mu \mathrm{L}$ (SSI, Lodi, CA, USA, Cat. no.: SSI-3320-00)

- $\quad$ PCR tubes $0.2 \mu \mathrm{L}$ (SSI, Lodi, CA, USA, Cat. no.: SSI-3225-00) 
- $\quad$ Tips for automatic pipettes $200 \mu \mathrm{L}, 1000 \mu \mathrm{L}, 5000 \mu \mathrm{L}$ (Axygen, Union, CA, USA; Cat. no.: TF-200-R-S, T-1000-B-R-S, T-5000-C)

- $\quad$ Surgical scissors, sterile (Surgicon, Punjab, Pakistan; Cat. no.: 1269184)

- $\quad$ Sharp-tipped metal J-16-140, sterile (Surgicon, Punjab, Pakistan; Cat. no.: 1269194)

- $\quad$ Cryotubes, sterile (Deltalab S.L., Barcelona, Spain; Cat. no.: 409106.1)

- $\quad$ PCR plates; 96-well; ABI-compatible (SSI, USA, Cat. no.: SSI-3425-00)

- $\quad$ Gibco ${ }^{\circledR}$ AmnioMAX ${ }^{\mathrm{TM}}$ C-100 Complete Medium (Thermo Fisher Scientific, Waltham, MA, USA; Cat. no.: 12558011)

- $\quad$ Gibco ${ }^{\circledR}$ AmnioMAX ${ }^{\mathrm{TM}}$ C-100 Basal Medium (Thermo Fisher Scientific, Waltham, MA, USA; Cat. no.: 17001074)

- $\quad$ Gibco ${ }^{\circledR}$ AmnioMAX ${ }^{\mathrm{TM}}$ C-100 Supplement (Thermo Fisher Scientific, Waltham, MA, USA; Cat. no.: 12556023)

- $\quad$ Eagle's MEM nutrient medium (BioloT, SaintPetersburg, Russia; Cat. no.: 1.3.3.)

- Collagenase type IV (Clostridium histolyticum), 200 U/mL(Sigma Aldrich, Steinheim, Germany; Cat. no.: Si C5138-1G)

- $\quad 1 \times 0.25 \%$ trypsin solution (BioloT, SaintPetersburg, Russia; Cat. no.: 1.2.2.5.)

- $\quad 0.3 \%$ Versen's solution (BioloT, SaintPetersburg, Russia; Cat. no.: 1.2.3.2.)

- $\quad$ Sterile saline solution $0.9 \% \mathrm{NaCl}$ (BioFarmGarant, Vladimir, Russia; Cat. no.: 322664)

- DPBS without Ca and Mg (SigmaAldrich, Steinheim, Germany; Cat. no.: 59331C1000ML)

- $\quad 96^{\circ}$ ethyl alcohol P.O.A. (Merck, Gernsheim, Germany; Cat. no.: 8.18760.1000)

- Penicillin-Streptomycin Solution $10.000 \mathrm{IU} / \mathrm{mL}$ (Gibco, ThermoFisher Scientific, Waltham, MA, USA; Cat. no.: 15140122)

- $\quad$ Kit for reverse transcription with MMLV-RH (DiAM, Moscow, Russia; Cat. no.: 1967.0050)

- $\quad$ RT-PCR Kit with EVA Green dye (Syntol, Moscow, Russia; Cat. no.: R-441)

- $\quad$ Fetal bovine serum (BioloT, SaintPetersburg, Russia; Cat. no.: 1.1.10.7.)

- Dimethylsulfoxide (DMSO) (VWR (Amresco), Mont-Royal, QC, Canada; Cat. no.: Am-0231-0.1)

- $\quad$ RNAlater ${ }^{\mathrm{TM}}$ solution (Invitrogen, Thermo Fisher Scientific, Waltham, MA, USA; Cat. no.: Am-7020)

- $\quad$ Big Dye Terminator v.3.1 Kit (Applied Biosystems, Troy, NY, USA; Cat. no.:4337455)

- $\quad$ Big Dye XTerminator Purification Kit (Applied Biosystems, Troy, NY, USA; Cat. no.: 4376487)

- $\quad$ Kit for reverse transcription (Syntol, Moscow, Russia; Cat. no.: OT-1)

- $\quad$ Mixture of dNTP, $10 \mathrm{mM}(10 \mu \mathrm{mol})$ each (Syntol, Moscow, Russia; Cat. no.: N1103)

- Taq polymerase, buffer without $\mathrm{Mg}^{2+}$ and $25 \mathrm{mM} \mathrm{MgCl}_{2}$ (Syntol, Moscow, Russia; Cat. no.: E0120)

\subsection{Equipment}

- $\quad$ Set of automatic pipettes volume 10-100 $\mu \mathrm{L}, 100-1000 \mu \mathrm{L}, 1000-5000 \mu \mathrm{L}$ (Sartorius BIOHIT, Göttingen, Germany; Cat. no.: 725050,725070, 725080)

- $\quad$ Biosafety Cabinet Class II (Laminar systems, Miass, Russia; Cat. no.: 1R-D.001-12ada)

- Ultraviolet germicidal irradiator (recirculator) Desar (Himmedservis, Tver, Russia; Cat. no.: av345)

- $\quad$ Centrifuge for $15 \mathrm{~mL}$ tubes up to $2300 \times g$ (ELMI Ltd., Riga, Latvia; Cat. no.: Elmi CM-6M)

- $\quad$ Centrifuge MiniSpin (Eppendorf, Hamburg, Germany; Cat. no.: 00000030762)

- $\quad \mathrm{CO}_{2}$ incubator MCO-19AIC(UV)(SANYO Electr. Co., Osaka, Japan; Cat. no.: SA-MCO19)

- Incubator $+37^{\circ} \mathrm{C}$ (Memmert, Germany; Cat. no.: 9537930)

- Two-compartment refrigerator: $+40^{\circ} \mathrm{C}$ and $-20{ }^{\circ} \mathrm{C}$ (POZIS, Zelenodolsk, Tatarstan, Russia; Cat. no.: 00000031036)

- $\quad$ Refrigerator $-80{ }^{\circ} \mathrm{C}$ (SANYO Electr. Co., Osaka, Japan; Cat. no.: MDF-U32V)

- Inverted microscope MIBR with a digital camera (LOMO, Saint Petersburg, Russia; Cat. no.: 00000074356)

- $\quad$ Centrifuge mini-vortex microspin (BIOSAN, Riga, Latvia; Cat. no.: 00000026197) 
- Thermocycler Rotor-Gene 3000 (Corbett Research, Mortlake, NSW, Australia)

- $\quad$ Laboratory roller mixer-rotator (BIOSAN, Riga, Latvia; Cat. no.: BS-010133-AAG)

- Capillary genetic analyzer (Sanger DNA sequencer) (Applied Biosystems, Carlsbad, CA, USA; Cat. no.: A28978)

- $\quad$ Thermocycler T100 (BIO-RAD, Hercules, CA, USA; Cat. no.: 00010014822)

\section{Procedure}

3.1. Obtaining Primary Cell Culture from Fragments of Collagenase-Treated Leiomyoma Nodules

$\triangle$ CRITICAL STEP One hour before handling the material, turn on the Desar and UV lamp in the Biosafety Cabinet Class II. Ensure that all the procedures are completed under sterile conditions.

1. Wash tumor fragments, total volume not less than $3.0-3.5 \mathrm{~cm}^{3}$, in three changes of saline, then place in a Petri dish with $15 \mathrm{~mL}$ of saline and shred into fragments about $3 \times 3 \times 3 \mathrm{~mm}$ in diameter using a scalpel (scissors).

2. Then, transfer the tissue fragments to $15 \mathrm{~mL}$ centrifuge tubes with $5 \mathrm{~mL}$ of Eagle's MEM nutrient medium (Biolot, Saint-Petersburg, Russia) and $2.5 \mathrm{mg}$ of type IV collagenase (Sigma Aldrich, Saint Louis, MO, USA), which corresponds to enzyme activity of $200 \mathrm{U} / \mathrm{mL}$.

3. Incubate tubes with tumor fragments in a tilted position for $90-120 \mathrm{~min}$ at $37^{\circ} \mathrm{C}$, shake or resuspend periodically.

4. After incubation, add $5 \mathrm{~mL}$ of DPBS to the tubes and resuspend the tissue fragments using a 5-mL automatic pipette to obtain a cell suspension.

5. Then, centrifuge the cells for $10 \mathrm{~min}$ at $200 \times g$, remove the supernatant, and separate the precipitate.

6. Then, add $5 \mathrm{~mL}$ of DPBS to the tubes again, well resuspend the precipitate, and centrifuge for $10 \mathrm{~min}$ at $200 \times g$, remove the supernatant, and resuspend the precipitate again.

7. Then, add $2 \mathrm{~mL}$ of pre-diluted AmnioMax Basal Medium with AmnioMax Supplement serum to the tubes. Transfer the resulting suspension to culture flasks T-25 (Thermo Fisher Scientific, Waltham, MA, USA) using a disposable sterile Pasteur pipette and incubate for $12-18$ days at $37^{\circ} \mathrm{C}$ and $5 \% \mathrm{CO} 2$ to reach $80 \%$ confluence. Then the culture medium should be changed every 3-4 days.

8. When primary (p0) UL cultures reach $80 \%$ confluence (Figure $2 \mathrm{a}$ ), they can be used for experiments or for the first passaging. We recommend taking at least $10-15 \%$ of p0 cells to achieve $80 \%$ confluence of p1 culture in 7-12 days. The viability of cells after passage can be monitored by the Trypan Blue exclusion test.

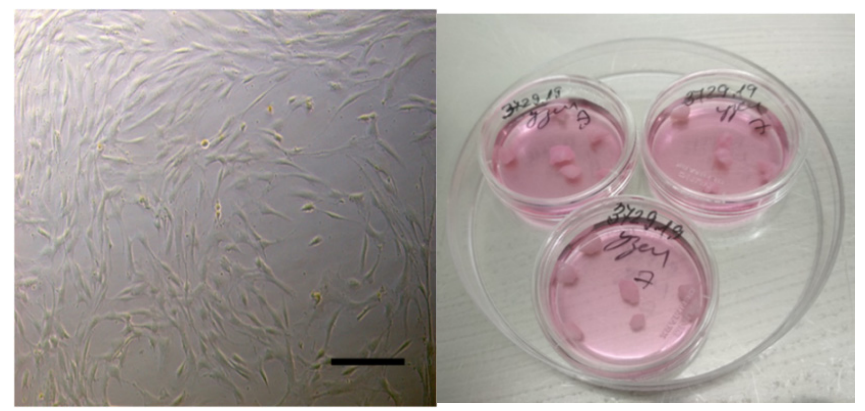

(a)

(b)

Figure 2. Representative microphotographs of the cellular and organotypic UL models: (a) primary UL cells at p0 (magnification $\times 100$; scale bar is $100 \mu \mathrm{m}$ ); (b) typical appearance of leiomyoma fragments.

\subsection{Freezing of Leiomyoma Cell Cultures and Nucleic Acid Isolation}

A CRITICAL STEP The following protocol steps should be performed in the Biosafety Cabinet Class II. 
1. Wash the cells twice with Versen's solution.

2. Remove the cells by adding $700 \mu \mathrm{L}$ of Trypsin-Versen solution to each well (1:3 ratio).

3. Incubate for $4-5 \mathrm{~min}$ at $+37^{\circ} \mathrm{C} .4$.

4. Add $5.0 \mathrm{~mL}$ of $0.9 \% \mathrm{NaCl}$ and gently wash cells from the bottom of the vial.

5. Transfer the cell suspension to $15.0 \mathrm{~mL}$ centrifuge tubes.

6. Then, centrifuge the cells for $10 \mathrm{~min}$ at $200 \times g$, remove the supernatant, and separate the precipitate.

7. Then, add $5 \mathrm{~mL}$ of DPBS to the tubes again, well resuspend the precipitate, and centrifuge for $10 \mathrm{~min}$ at $200 \times g$, then remove the supernatant.

8. Add $300 \mu$ Lof DPBS solution without $\mathrm{Ca}$ and $\mathrm{Mg}$, mix gently.

9. Transfer $100 \mu \mathrm{L}$ of the cell suspension to a $2.0 \mathrm{~mL}$ tube containing $1.0 \mathrm{~mL}$ of RNA stabilizer. Leave at room temperature for $1 \mathrm{~h}$. Then use for RNA isolation or store in a $-80{ }^{\circ} \mathrm{C}$ freezer for up to 1 year if necessary.

10. Transfer $100 \mu \mathrm{L}$ of cell suspension to a $2.0 \mathrm{~mL}$ dry tube and use for DNA extraction. If necessary, store in $\mathrm{a}-80^{\circ} \mathrm{C}$ freezer for up to 1 year.

11. Transfer $100 \mu \mathrm{L}$ of cell suspension to a $2.0 \mathrm{~mL}$ cryotube containing a mixture of $100 \mu \mathrm{L}$ dimethyl sulfoxide and $900 \mu \mathrm{L}$ bovine serum. Mix gently by pipetting. Cryotubes should bescrewed thoroughly. Label cryovials with a water- and low-temperature resistant marker. Label cryoprobes with the date, culture name, and passage. If necessary, store in a freezer at $-80{ }^{\circ} \mathrm{C}$ for no more than 1 year. According to our observations, when p0 leiomyoma cell lines are thawed, cells carrying the MED12 mutation and/or increased expression of the HMGA2 gene are preserved in p1 culture.

\subsection{Organotypic Model from Native Fragments of Leiomyoma Nodules}

1. Using scissors or a scalpel, divide a large fragment of the node into smaller ones (approximately $3 \times 3 \times 3$ or $4 \times 4 \times 4 \mathrm{~mm}$ ) in the number necessary for subsequent experiments.

2. Transfer 5-7 fragments to each $35 \mathrm{~mm}$ diameter Petri dish (Figure $2 \mathrm{~b}$ ).

3. Add $1.0 \mathrm{~mL}$ of Gibco ${ }^{\circledR}$ AmnioMAX ${ }^{\mathrm{TM}} \mathrm{C}-100$ Complete Medium. Place in a $\mathrm{CO}_{2}$ incubator. According to literature data and personal observations, cells in tumor slices remain viable at least for 7-21 days [10]. It is recommended to keep tumor fragments ex vivo in culture for up to 7 days with the medium change every 3-4 days when using them in experimental work.

A CRITICAL STEP The culture medium should not completely cover the fragments, providing contact with air (10-15\% of the fragment surface) in the $\mathrm{CO}_{2}$ incubator and preventing it from floating up. According to our observations, on the $5-7$ th day of cultivation, the cells begin to migrate into the culture medium and ensure the fixation of the UL fragment on the substrate.

\subsection{MED12 Mutation Analysis}

Analysis of MED12 exon 2 mutations was performed as described previously by direct PCR sequencing of genomic DNA according to the protocol repeatedly used in our laboratory [11,12].

\subsection{Reverse Transcription of RNA and HMGA2 Gene Expression Analysis}

3.5.1. Reverse Transcription of RNA

Reverse transcription of RNA was performed using the kit for reverse transcription "OT-1" (Syntol, Moscow, Russia) according to the manufacturer's instructions. The reverse transcription kit is based on recombinant reverse transcriptase, which is a product of the pol gene of Moloney Murine Leukemia Virus (M-MLV).

1. Perform eachreaction in a total volume of $20 \mu \mathrm{L}$ containing $10 \mathrm{mmol} \mathrm{d}-\mathrm{NTP}$ and $200 \mathrm{U} / \mathrm{mL}$ MMLUV in the presence of oligo-dT16 $(2.5 \mathrm{mM})$ and random hexamers $(3 \mathrm{mg} / \mathrm{mL}$ ) with the addition of 100 to $500 \mathrm{ng}$ total RNA. 
2. Place strips of random oligonucleotide hexamers with the reaction mixture into Thermocycler T100. The reverse transcription reaction was performed at: $+25^{\circ} \mathrm{C}-10 \mathrm{~min}$; $+37{ }^{\circ} \mathrm{C}-120 \mathrm{~min} ;+85{ }^{\circ} \mathrm{C}-5 \mathrm{~min} ;+4{ }^{\circ} \mathrm{C}-5 \mathrm{~min}$. The cDNA was stored at $+4{ }^{\circ} \mathrm{C}$. The obtained cDNA was used for real-time PCR.

\subsubsection{HMGA2 Gene Expression Analysis}

Calibration curve preparation for Real-Time PCR

1. $12 \mu \mathrm{L} \mathrm{cDNA}$ mixture $[\mathrm{x} \mathrm{ng} / \mathrm{mkl}]+12 \mu \mathrm{L} \mathrm{H}_{2} \mathrm{O}$, stir by pipetting, incubate for $10 \mathrm{~min}$.

2. $12 \mu \mathrm{L}$ of $[\mathrm{x} / 2 \mathrm{ng} / \mathrm{mkl}] \mathrm{cDNA}$ mixture $+12 \mu \mathrm{L} \mathrm{H} \mathrm{H}_{2} \mathrm{O}$, stir by pipetting, incubate for $10 \mathrm{~min}$.

3. $12 \mu \mathrm{L}$ of $[x / 4 \mathrm{ng} / \mathrm{mkl}]$ cDNA mixture $+12 \mu \mathrm{L} \mathrm{H} \mathrm{H}_{2} \mathrm{O}$, stir by pipetting, incubate for $10 \mathrm{~min}$.

4. $12 \mu \mathrm{L}$ of $[x / 8 \mathrm{ng} / \mathrm{mkl}]$ cDNA mixture $+12 \mu \mathrm{L} \mathrm{H} \mathrm{H}_{2} \mathrm{O}$, stir by pipetting, incubate for $10 \mathrm{~min}$.

5. $12 \mu \mathrm{L}$ of $[\mathrm{x} / 16 \mathrm{ng} / \mathrm{mkl}] \mathrm{cDNA}$ mixture $+12 \mu \mathrm{L} \mathrm{H}_{2} \mathrm{O}$, stir by pipetting, incubate for $10 \mathrm{~min}$.

6. The calibration dilutions must be stored at $-20^{\circ} \mathrm{C}$.

Real-Time PCR.

$\triangle$ CRITICAL STEP The following steps of the protocol are performed in the PCR box.

1. Take out the strips and the lids for the strips using tweezers.

2. In $1.5 \mathrm{~mL}$ tubes (or $2 \mathrm{~mL}$-depending on the number of samples), make separate mixtures for each set of primers at a concentration of 5 pmol (HMGA2 gene: forward 5'-AGA GTC CCT CTA AAG CAG CTC A-3'; reverse 5'-CAA CTG CTGCTG AGG TAG AAA TCG- $\left.3^{\prime}\right)$, including primers to the housekeeping gene ( $\beta$-actingene: $5^{\prime}$-TGC CGA CAG GAT GCA GAA G-3'; reverse 5'-GCC GAT CCACAC GGA GTA CT-3'). Tubes for the mixtures should be wrapped in foil.

3. Scheme of mixture preparation (per sample taking into account prepared standards and one blank sample; in order of adding reagents):

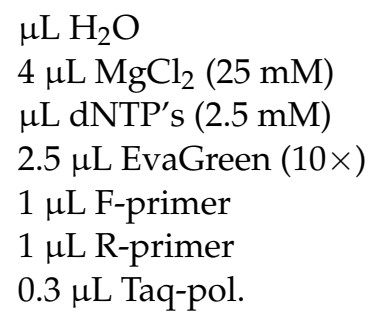

4. Stir the mixture by pipetting; pipette into $22.5 \mu \mathrm{L}$ strips. Try to dig close to the bottom of the strips; do not leave any droplets on the walls at the top.

5. Using separate spouts, dig $2.5 \mu \mathrm{L}$ of cDNA into strips. Drop each sample in two replicates.

6. Close the test tubes with caps. Place in the amplifier Rotor-Gene 3000 (Corbett, Australia) and run the appropriate program (Single cycle $95^{\circ}-5 \mathrm{~min}$; then 38 cycle: $94^{\circ}-15 \mathrm{~s} ; 600-60 \mathrm{~s}$. Then heating from $60^{\circ}$ to $95^{\circ}$ in 0.5 degree increments, $10 \mathrm{~s}$ each step).

7. The relative level of mRNA expression was calculated by the $\Delta \Delta \mathrm{Ct}$ method (Livak method) using ExpressionSuit V1.0.3 software.

\section{Expected Results}

Primary cell and tissue fragments taken directly from the body represent the most accurate models for in vitro studies. In the case of uterine leiomyoma, despite monoclonal origin, various cell populations can be found, including smooth muscle, fibroblasts, and stem cells, embedded in an abundant extracellular matrix $[13,14]$. The communication between these cells is likely critical for UL proliferation and survival. At the same time, the rapid loss of mutated cells in the monolayer model does not affect in vitro growth 
as a result of as yet unknown mechanisms and indicates the need for soluble factors or components that are absent in the standard culture medium.

We propose using the complete Gibco ${ }^{\circledR}$ AmnioMAX ${ }^{\mathrm{TM}} \mathrm{C}-100$ medium specially designed to support the growth of various cell types to ensure the survival of monolayer primary cell culture and 3-dimensional organotypic model. It should be noted that we tested different media at the beginning of the protocol development (Figure S1). According to our observations, fibroblast-like cells migrating into the culture medium from fragments of myomatous nodes give rise to the first colonies, and they preserve a mutation in the MED12 gene for at least three weeks of culturing (Figure 2). It should be noted that the cells had good viability after passaging as it was determined by the Trypan Blue exclusion test; no more than $5 \%$ of cells were Trypan Blue-positive.

In order to minimize the loss of the cells carrying a driver mutation in the MED12 gene, we propose to use only the $\mathrm{p} 1$ subculture. Thus, we recommend increasing the UL tissue volume to obtain cell culture at the first passage (p0). The mutation preservation was confirmed by the screening of MED12 exon 2 mutations using Sanger sequencing (Figure 3).

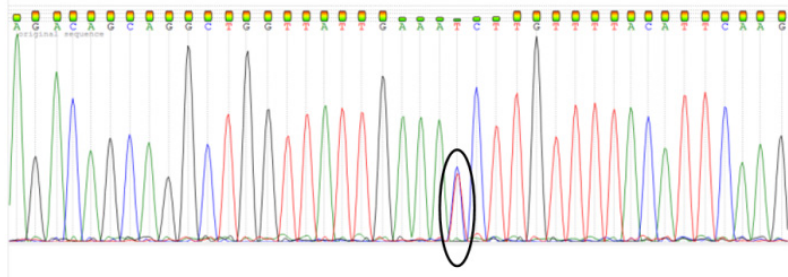

${ }_{\Lambda}$

(a)

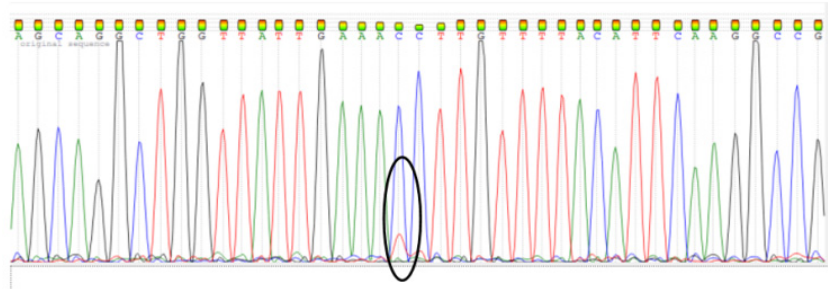

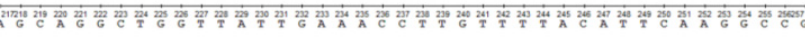

(c)
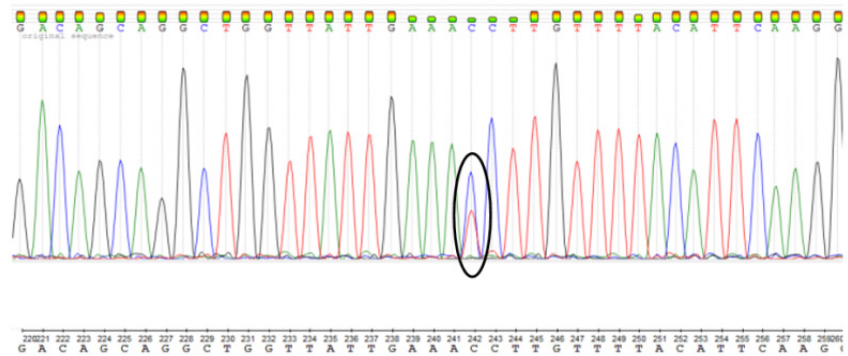

(b)

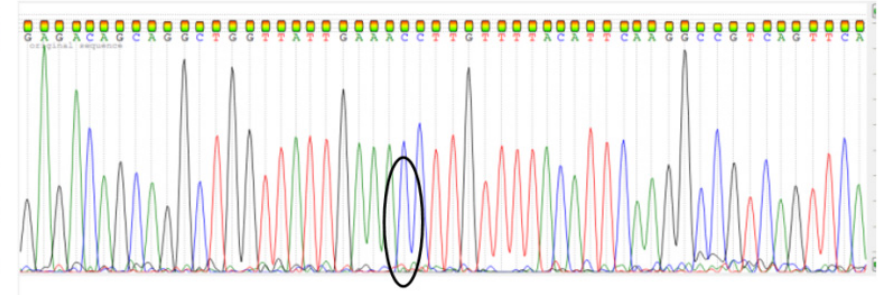

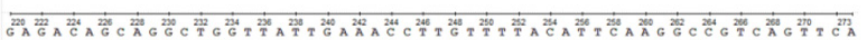

(d)

Figure 3. Detection of heterozygous mutation c.131G >A in MED12 gene in the same primary UL cell line at different passages: (a) p1; (b) p2; (c) p3; (d) control-healthy myometrium.

The presence of HMGA2 gene expression, another genetic alteration in UL was confirmed by the RT-qPCR method (Figure 4). It can be seen that the HMGA2 gene expression level significantly decreases with the higher passage.

Thus, we recommend using at least $30 \mathrm{~mm}^{3}$ volume of initial tissue before starting the isolation of UL cells. After the collagenase treatment and subsequent cell culturing during 1-2 weeks, $2-3$ flasks with $80 \%$ confluency $\left(0.8-1.5 \times 10^{6}\right.$ UL cells) can be obtained. It is worth noting that due to individual heterogeneity between leiomyomas, there may be a difference in proliferation rate per each UL line. According to our observations, most UL lines doubled every $24 \mathrm{~h}$. The obtained UL lines at p0 can be frozen or used directly for experimental work e.g., seeded at 24- or 48-well plates at p1.

In the case of the organotypic model, we found that the MED12 gene mutations and HMGA2 gene expression-two main drivers of UL pathogenesis-remain preserved for at least 14 days of culturing. For viability evaluation, the UL fragments were transferred to a new Petri dish on days 7, 14, and 21 to obtain cultures of cells that migrated from the UL 
fragments. The viability of migrated cells was monitored by the Trypan Blue exclusion test. The percentage of Trypan Blue-positive cells did not exceed 5\%. All the cell lines obtained in this way had the same mutations in the MED12 gene as a parent UL fragment.

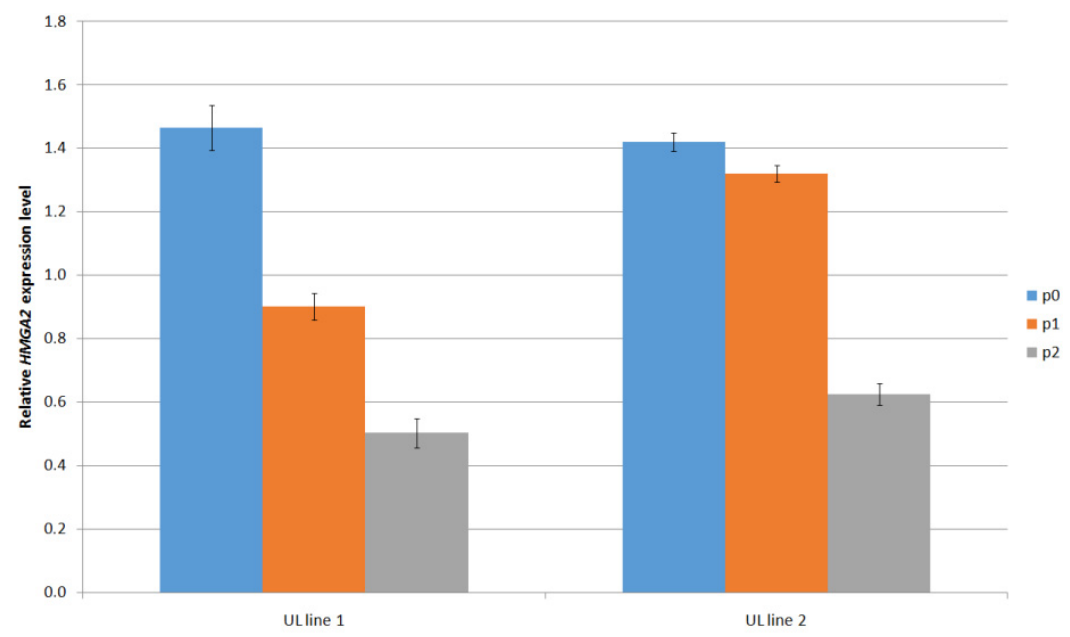

Figure 4. Measurement of HMGA2 gene expression (fold change relative to reference $\beta$-actin gene) in two independent primary UL cell lines at different passages.

It should be noted that cultured UL fragments retain their morphology as it was assessed by hematoxyline-eosin stainingon days 7, 14, and 21 (Figure 5 and Figure S2). In the stained sections, a densely packed, disorganized pattern of extracellular matrix (marked by arrows) and fibrous connecting tissue can be seen.

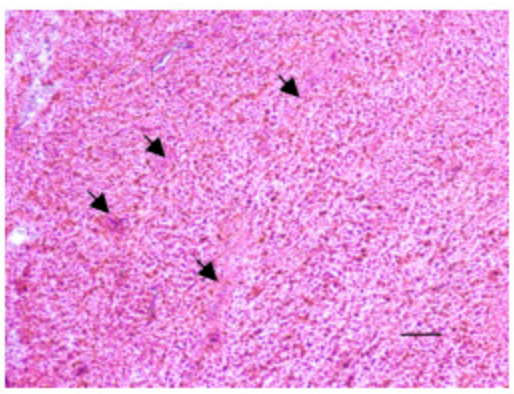

(a)

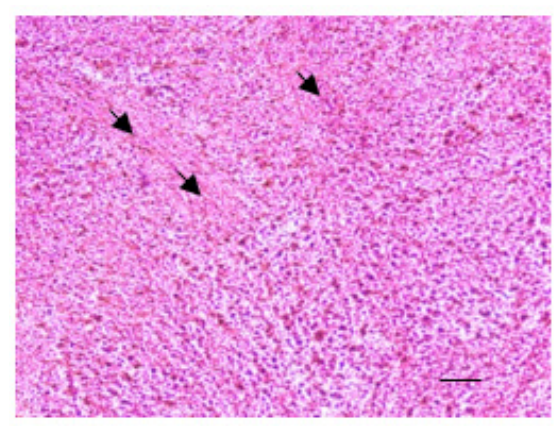

(b)

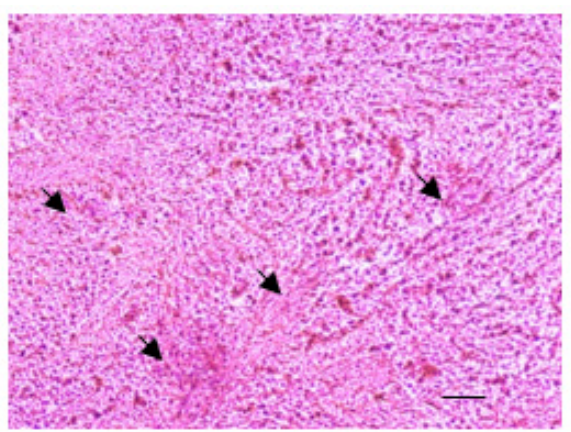

(c)

Figure 5. Histological characterization of the organotypic model. Hematoxyline-eosine stained cryosections of UL fragments after 7 (a), 14 (b), and 21 (c) days of culture (magnification $\times 100$; scale bar is $200 \mu \mathrm{m})$. Arrows mark extracellular matrix.

Supplementary Materials: The following supporting information can be downloaded at: https: / / www.mdpi.com/article/10.3390/mps5010016/s1, Figure S1: Detection of heterozygous mutation c. $131 \mathrm{G}^{>} \mathrm{A}$ in MED12 gene in the same primary UL cell line at passages $\mathrm{p} 0$ and p1 cultured with AmnioMAX ${ }^{\mathrm{TM}}$ C-100 or DMEM F-12 medium; Figure S2: Histological characterization of the organotypic model. Hematoxyline-eosine stained cryosections of UL fragments after 7, 14 and 21days of culture (magnification $\times 200$ ).

Author Contributions: Conceptualization, A.E. and N.S.; methodology, N.S.; formal analysis, A.K.; investigation, N.S., A.E. and N.O.; resources, N.S.; writing-original draft preparation, N.S. and A.K.; writing-review and editing, A.K.; supervision, A.E.; project administration, A.K.; funding acquisition, A.E. All authors have read and agreed to the published version of the manuscript.

Funding: This research was funded by the Russian Science Foundation, grant number 21-15-00111. 
Institutional Review Board Statement: The study was conducted according to the guidelines of the Declaration of Helsinki and approved by the Ethics Committee of D.O. Ott Research Institute of Obstetrics, Gynecology and Reproductology (protocol 89 was approved 22 December 2017).

Informed Consent Statement: Informed consent was obtained from all subjects involved in the study.

Data Availability Statement: The data presented in this study are available on request from the corresponding author. The data are not publicly available due to restrictions of the subjects' agreement.

Conflicts of Interest: The authors declare no conflict of interest.

\section{References}

1. Ohara, N. Action of progesterone receptor modulators on uterine leiomyomas. Clin. Exp. Obstet. Gynecol. 2008, 35, 165-166. [PubMed]

2. Zhu, Y.; Zhang, T.; Xie, S.; Tu, R.; Cao, Y.; Guo, X.; Zhou, J.; Zhou, X.; Cao, L. Gestrinone inhibits growth of human uterine leiomyoma may relate to activity regulation of ER $\alpha$, Src and P38 MAPK. Biomed. Pharmacother. 2012, 66, 569-577. [CrossRef] [PubMed]

3. Segars, J.H.; Parrott, E.C.; Nagel, J.D.; Guo, X.C.; Gao, X.; Birnbaum, L.S.; Pinn, V.W.; Dixon, D. Proceedings from the third national institutes of health international congress on advances in uterine leiomyoma research: Comprehensive review, conference summary and future recommendations. Hum. Reprod. Update 2014, 20, 309-333. [CrossRef] [PubMed]

4. Shtykalova, S.V.; Egorova, A.A.; Maretina, M.A.; Freund, S.A.; Baranov, V.S.; Kiselev, A.V. Molecular Genetic Basis and Prospects of Gene Therapy of Uterine Leiomyoma. Russ. J. Genet. 2021, 57, 1002-1016. [CrossRef]

5. Nadine Markowski, D.; Tadayyon, M.; Bartnitzke, S.; Belge, G.; Maria Helmke, B.; Bullerdiek, J. Cell cultures in uterine leiomyomas: Rapid disappearance of cells carrying MED12 mutations. Genes Chromosomes Cancer 2014, 53, 317-323. [CrossRef] [PubMed]

6. Holzmann, C.; Markowski, D.N.; Bartnitzke, S.; Koczan, D.; Helmke, B.M.; Bullerdiek, J. A rare coincidence of different types of driver mutations among uterine leiomyomas (UL). Mol. Cytogenet. 2015, 8, 76. [CrossRef] [PubMed]

7. Bloch, J.; Holzmann, C.; Koczan, D.; Helmke, B.M.; Bullerdiek, J. Factors affecting the loss of MED12-mutated leiomyoma cells during in vitro growth. Oncotarget 2017, 8, 34762-34772. [CrossRef] [PubMed]

8. Klemke, M.; Meyer, A.; Nezhad, M.H.; Bartnitzke, S.; Drieschner, N.; Frantzen, C.; Schmidt, E.H.; Belge, G.; Bullerdiek, J. Overexpression of HMGA2 in uterine leiomyomas points to its general role for the pathogenesis of the disease. Genes Chromosomes Cancer 2009, 48, 171-178. [CrossRef] [PubMed]

9. Wang, J.; Ohara, N.; Takekida, S.; Xu, Q.; Maruo, T. Comparative effects of heparin-binding epidermal growth factor-like growth factor on the growth of cultured human uterine leiomyoma cells and myometrial cells. Hum. Reprod. 2005, 20, 1456-1465. [CrossRef] [PubMed]

10. Salas, A.; López, J.; Reyes, R.; Évora, C.; de Oca, F.M.; Báez, D.; Delgado, A.; Almeida, T.A. Organotypic culture as a research and preclinical model to study uterine leiomyomas. Sci. Rep. 2020, 10, 5212. [CrossRef] [PubMed]

11. Osinovskaya, N.S.; Malysheva, O.V.; Shved, N.Y.; Ivashchenko, T.E.; Sultanov, I.Y.; Efimova, O.A.; Yarmolinskaya, M.I.; Bezhenar, V.F.; Baranov, V.S. Frequency and Spectrum of MED12 Exon 2 Mutations in Multiple Versus Solitary Uterine Leiomyomas From Russian Patients. Int. J. Gynecol. Pathol. 2016, 35, 509-515. [CrossRef] [PubMed]

12. Dzhemlikhanova, L.K.; Efimova, O.A.; Osinovskaya, N.S.; Parfenyev, S.E.; Niauri, D.A.; Sultanov, I.Y.; Malysheva, O.V.; Pendina, A.A.; Shved, N.Y.; Ivashchenko, T.E.; et al. Catechol-O-methyltransferase Val158Met polymorphism is associated with increased risk of multiple uterine leiomyomas either positive or negative for MED12 exon 2 mutations. J. Clin. Pathol. 2017, 70, 233-236. [CrossRef] [PubMed]

13. Islam, M.S.; Protic, O.; Ciavattini, A.; Giannubilo, S.R.; Tranquilli, A.L.; Catherino, W.H.; Castellucci, M.; Ciarmela, P. Tranilast, an orally active antiallergic compound, inhibits extracellular matrix production in human uterine leiomyoma and myometrial cells. Fertil. Steril. 2014, 102, 597-606. [CrossRef] [PubMed]

14. Moore, A.B.; Yu, L.; Swartz, C.D.; Zheng, X.; Wang, L.; Castro, L.; Kissling, G.E.; Walmer, D.K.; Robboy, S.J.; Dixon, D. Human uterine leiomyoma-derived fibroblasts stimulate uterine leiomyoma cell proliferation and collagen type I production, and activate RTKs and TGF beta receptor signaling in coculture. Cell Commun. Signal. 2010, 8, 10. [CrossRef] [PubMed] 